\title{
PÓ DE FORNO ELÉTRICO DE SIDERURGIA COMO FONTE DE MICRONUTRIENTES E DE CONTAMINANTES PARA PLANTAS DE MILHO'
}

\author{
ADRIANAMARIA DEAGUIARACCIOLY², ANTONIO EDUARDO FURTINI NETO3, \\ JOELAUGUSTO MUNIZ ${ }^{4}$, VALDEMAR FAQUIN ${ }^{5}$ e GERALDOAPARECIDO DEAQUINO GUEDES ${ }^{6}$
}

\begin{abstract}
RESUMO - O objetivo deste trabalho foi avaliar o pó de forno elétrico (PFE), resíduo da indústria siderúrgica, como fonte de micronutrientes e contaminantes para o milho, em condições de casa-devegetação. Utilizou-se como substrato um Cambissolo álico, onde foram aplicados três níveis de calcário $\left(0,2\right.$ e $\left.4 \mathrm{t} \mathrm{ha}^{-1}\right)$ e cinco tratamentos: sem fornecimento de micronutrientes (testemunha), com fornecimento de micronutrientes via fontes de reagentes p.a., e com 250,500 e $1.000 \mathrm{~kg} \mathrm{ha}^{-1}$ do pó de forno elétrico. A produção de matéria seca só variou significativamente na presença de calagem. Os tratamentos com PFE proporcionaram aumentos na produção de biomassa em relação à testemunha, porém apresentaram resultados inferiores aos proporcionados pela aplicação de micronutrientes via fontes p.a. Não ocorreram diferenças entre os tratamentos na produção de matéria seca do milho com a adição de doses crescentes de PFE. O PFE atuou como fonte de micronutrientes, principalmente de Zn e de Fe. A solubilidade do PFE é sensivelmente maior em condições de maior acidez do solo. A presença de $\mathrm{Cd}$ e $\mathrm{Pb}$ foi detectada na matéria seca da parte aérea. O risco de contaminação do solo e dos alimentos por metais pesados presentes no PFE pode limitar seu uso agrícola como fonte de micronutrientes.
\end{abstract}

Termos para indexação: resíduo siderúrgico, oligoelementos, metais pesados, nutrientes minerais, solo.

\section{STEEL INDUSTRY FURNACE RESIDUE AS A SOURCE OF MICRONUTRIENTS AND CONTAMINANTS TO CORN PLANT}

\begin{abstract}
The residue of siderurgic furnace was tested as a source of micronutrients and contaminants to corn plants at greenhouse condition, in Lavras, MG, Brazil. Soil material of an Inceptsol (allic Cambisol) was used as substrate, which received 0,2 and 4 ton ha ${ }^{-1}$ of liming material and the following treatments: blank, micronutrient as p.a. reagent, and 250,500 , and $1,000 \mathrm{~kg} \mathrm{ha}^{-1}$ of the furnace residue. Liming dose was the main factor accounting for the differences in dry matter production. The residue increased biomass production in relation to check, but facing to p.a. reagents results were lower; there were no significant differences due to doses of this product. Also the residue supplied mainly Zn and Fe to corn plants. Solubility of this by product is higher as soil acidity increases. It was detected the presence of $\mathrm{Cd}$ and $\mathrm{Pb}$ in the shoot dry mass of corn. The potential risk of soil and food contamination must be taken into account when using this furnace residue as source of micronutrient.
\end{abstract}

Index terms: siderurgical residue, trace elements, heavy metals, mineral nutrients, soil.

${ }_{1}^{1}$ Aceito para publicação em 21 de dezembro de 1999 Extraído da Dissertação de Mestrado apresentada pelo primeiro autor à Universidade Federal de Lavras (UFLA).

${ }^{2}$ Eng. Agrôn., M.Sc., Aluna de pós-graduação, UFLA, Caixa Postal 37, CEP 37200-000 Lavras, MG. Bolsista do CNPq. E-mail: accioly@ufla.br

${ }^{3}$ Eng. Agrôn., Dr., Prof. Adjunto, Dep. de Ciência do Solo, UFLA. Bolsista do CNPq. E-mail: afurtini@ufla.br

${ }^{4}$ Eng. Agrôn., Dr., Prof. Titular, Dep. de Ciências Exatas, UFLA. E-mail: joamuniz@ufla.br

${ }^{5}$ Eng. Agrôn., Dr., Prof. Titular, Dep. de Ciência do Solo, UFLA. Bolsista do CNPq. E-mail: vafaquin@ufla.br

${ }^{6}$ Eng. Agrôn., Ph.D., Prof. Titular, Dep. de Ciência do Solo, UFLA. E-mail: des@ufla.br

\section{INTRODUÇÃO}

No Brasil, a produtividade de algumas culturas vem sendo seriamente limitada, em algumas regiões, pela deficiência de micronutrientes. O problema é agravado em virtude da baixa fertilidade dos solos, pela remoção destes elementos nas colheitas e pelo uso crescente, e provavelmente incorreto, de calcário e adubos fosfatados, que contribuem para uma menor solubilidade dos micronutrientes (Bataglia \& Raij, 1989). 
Com a implantação do parque siderúrgico brasileiro, a geração de resíduos tem-se tornado um problema grave, em razão dos impactos que esses materiais podem causar aos ecossistemas terrestres e aquáticos (Amaral Sobrinho et al., 1993). Desse modo, é importante que sejam intensificadas as pesquisas integradas de aproveitamento dos resíduos industriais e urbanos, como uma maneira viável de minimizar tais impactos ou como alternativa para a produção de corretivos e fertilizantes.

O emprego de alguns resíduos siderúrgicos como fertilizantes e corretivos agrícolas tem-se mostrado uma alternativa viável para o aproveitamento dos subprodutos de siderurgia. Esses resíduos apresentam, geralmente, teores elevados de micronutrientes (Malavolta, 1994). Entretanto, na utilização desses materiais é necessário considerar-se, também, o teor de metais pesados que, em níveis elevados, podem tornar-se tóxicos e limitar seu uso na atividade agrícola.

O pó de forno elétrico é um produto muito fino, de cor marrom-escuro, sem odor, gerado no forno elétrico de aciaria. A quantidade gerada no processo siderúrgico pode atingir um volume expressivo. O pó de forno elétrico é classificado como perigoso, tendo como poluentes potenciais o $\mathrm{Zn}, \mathrm{o} \mathrm{Pb}$, e, em menor escala, o Cd. Pode ter aplicações na construção civil (blocos de concreto, argamassa, cerâmica), na indústria (pigmentos para tinta; recuperação de $\mathrm{Zn}$ e Pb) e, na agricultura, como fertilizante (Siderúrgica Mendes Júnior, 1988).

A incorporação ao solo de resíduos industriais, ricos em metais pesados, pode ser uma prática viável, desde que se conheça a composição química do material e as propriedades físicas e químicas do solo (Pombo \& Klamt, 1986). Adinâmica dos metais pesados no sistema solo-planta é influenciada pelas características e propriedades dos solos, e pelo comportamento das diferentes espécies vegetais (Cabrera et al., 1988; Hagemeyer \& Waisel, 1989; Hernandez et al., 1991). Entretanto, como as doses de micronutrientes utilizadas são sempre pequenas, a adição de metais pesados, via resíduo, pode não ser expressiva, dependendo da composição química desses materiais.

O objetivo do presente trabalho foi avaliar o pó de forno elétrico da indústria siderúrgica como fonte de micronutrientes e contaminantes para o milho.

\section{MATERIAL E MÉTODOS}

O experimento foi conduzido em casa-de-vegetação do Departamento de Ciência do Solo da Universidade Federal de Lavras (UFLA), no período de agosto a dezembro de 1994, utilizando-se como substrato o material da camada superficial $(0-20 \mathrm{~cm})$ de um Cambissolo álico, textura média, coletado no município de Nazareno, MG. O material foi caracterizado quimicamente conforme Vettori (1969) com modificações (Embrapa, 1979): $\mathrm{pH}$ em água $(1: 2,5)=4,7 ; \mathrm{Al}^{3+}, \mathrm{Ca}^{2+}$ e $\mathrm{Mg}^{2+}$, extraídos com $\mathrm{KCl} 1 \mathrm{~mol} \mathrm{~L}^{-1}=0,8,0,4$ e $0,2 \mathrm{cmol}_{\mathrm{c}} \mathrm{dm}^{-3}$ de solo, respectivamente; $\mathrm{P}, \mathrm{K}, \mathrm{Zn}, \mathrm{Cu}, \mathrm{Fe}$ e $\mathrm{Mn}$ extraídos com Mehlich 1: 1, 31, 0,38, 0,41, 153,85 e 4,56 $\mathrm{mg} \mathrm{dm}^{-3} \mathrm{de}$ solo, respectivamente e $\mathrm{MO}, 21 \mathrm{~g} \mathrm{~kg}^{-1}$ de solo

$\mathrm{O}$ delineamento experimental utilizado foi o inteiramente casualizado, distribuído em esquema fatorial $3 \times 5$, com quatro repetições, sendo: três níveis de calcário $(0,2$ e $4 \mathrm{t} \mathrm{ha}^{-1}$ ) e cinco tratamentos envolvendo micronutrientes: testemunha; aplicação de micronutrientes via fontes puras (reagentes analíticos p.a.); e a aplicação de 250, 500 e $1.000 \mathrm{~kg} \mathrm{ha}^{-1}$ do pó de forno elétrico (PFE). O PFE foi fornecido pela Siderúrgica Mendes Júnior (Juiz de Fora, $\mathrm{MG}$ ), cuja composição química em teores totais de macronutrientes $\left(\mathrm{g} \mathrm{kg}^{-1}\right)$ e micronutrientes e metais pesados $\left(\mathrm{mg} \mathrm{kg}^{-1}\right)$, foi a seguinte: $\mathrm{N}, 0,0 ; \mathrm{P}, 1,8 ; \mathrm{K}, 26,0$; $\mathrm{Ca}, 40,3 ; \mathrm{Mg}, 8,2 ; \mathrm{Al}, 16,8 ; \mathrm{Fe}, 518.600 ; \mathrm{Mn}, 9.069$; $\mathrm{Zn}, 144.785 ; \mathrm{Cu}, 1.710$; Cd, 104 e Pb, 13.088. Uma subamostra do resíduo foi homogeneizada, seca ao ar, e passada em peneira com malha de $0,3 \mathrm{~mm}$ de abertura para uso no experimento. No tratamento com micronutrientes via fontes p.a., o fornecimento foi de 3,6, 1,3, 1,5 e 4,0 $\mathrm{mg} \mathrm{dm}^{-3}$ de solo de $\mathrm{Mn}, \mathrm{Cu}, \mathrm{Fe}$ e Zn, respectivamente.

A quantidade de calcário foi calculada com base na curva de incubação para se atingir $\mathrm{pH}$ igual a 5,5 e 6,5, equivalentes à aplicação de $2 \mathrm{e} 4 \mathrm{t} \mathrm{ha}^{-1}$ do corretivo, respectivamente, aplicado através de uma mistura de $\mathrm{CaCO}_{3}$ e $\mathrm{MgCO}_{3}$ p.a. na proporção equivalente de Ca: $\mathrm{Mg}$ de 4:1. A adubação básica de plantio correspondeu a 50, 200, 150, $30,0,8$ e $0,15 \mathrm{mg} \mathrm{dm}^{-3}$ de solo de $\mathrm{N}, \mathrm{P}, \mathrm{K}, \mathrm{S}, \mathrm{B}$ e $\mathrm{Mo}$, respectivamente. Aos 19 e 26 dias após a emergência, foram realizadas aplicações de $30 \mathrm{mg} \mathrm{dm}^{-3} \mathrm{de} \mathrm{N}$, perfazendo um total de $110 \mathrm{mg} \mathrm{dm}^{-3} \mathrm{de} \mathrm{N}$.

Em cada vaso, contendo $3,7 \mathrm{dm}^{3}$ de material do solo, foram semeadas seis sementes de milho da cultivar Cargill C 125, deixando-se, após o desbaste, duas plantas por vaso

Durante o cultivo, a umidade do solo foi mantida em $60 \%$ do volume total de poros (Freire et al., 1980), aferida 
por pesagem diária dos vasos, recuperando-se a massa inicial com água desmineralizada.

Aos 36 dias após a emergência, foi efetuado o corte das plantas de milho na altura do coleto, separando-se em parte aérea e raízes. Procedeu-se a secagem do material vegetal a $70^{\circ} \mathrm{C}$ em estufa, até atingir-se massa constante, e determinou-se a matéria seca da parte aérea (MSPA), raízes (MSRA) e total (MSTO). O material vegetal foi triturado em moinho tipo Willey e submetido à digestão nítrico-perclórica, para a determinação dos teores de $\mathrm{Zn}$, $\mathrm{Cu}, \mathrm{Fe}, \mathrm{Mn}, \mathrm{Cd}$ e $\mathrm{Pb}$. A concentração desses elementos no extrato foi determinada em espectrômetro de emissão óptica de plasma, na Embrapa-Centro Nacional de Pesquisa de Milho e Sorgo, Sete Lagoas, MG. A quantidade de nutrientes acumulada nos tecidos da parte aérea foi calculada com base na biomassa seca e na concentração dos elementos nos tecidos.

Calculou-se também, dentro de cada nível de calagem, a produção relativa de MSTO, considerando-se o tratamento com aplicação de micronutrientes via fontes p.a. como $100 \%$.

A produção de matéria seca e as concentrações e conteúdos de nutrientes e metais pesados nas plantas de milho foram avaliados através de análise de variância. As médias do fator micronutrientes foram comparadas por intermédio de contrastes ortogonais, testados pelo teste $\mathrm{F}$. Escolheram-se contrastes de interesse: o primeiro foi estabelecido para avaliar o efeito da aplicação de micronutrientes independentemente da fonte e dose; o segundo comparou o efeito da aplicação de micronutrientes via fontes p.a. com a aplicação via PFE; o terceiro e o quarto contrastes foram definidos para a comparação entre as doses do PFE. Os efeitos linear e quadrático, para um determinado fator com níveis eqüidistantes foram definidos por meio de contrastes (Banzatto \& Kronka, 1992) Os contrastes escolhidos foram:

$\mathrm{Y}_{1}=4 \mathrm{x}_{1}-\mathrm{x}_{2}-\mathrm{x}_{3}-\mathrm{x}_{4}-\mathrm{x}_{5}$,

$\mathrm{Y}_{2}=0 \mathrm{x}_{1}+3 \mathrm{x}_{2}-\mathrm{x}_{3}-\mathrm{x}_{4}-\mathrm{x}_{5}$

$\mathrm{Y}_{3}=0 \mathrm{x}_{1}+0 \mathrm{x}_{2}-\mathrm{x}_{3}+0 \mathrm{x}_{4}+\mathrm{x}_{5}, \mathrm{e}$

$\mathrm{Y}_{4}=0 \mathrm{x}_{1}+0 \mathrm{x}_{2}+\mathrm{x}_{3}-2 \mathrm{x}_{4}+\mathrm{x}_{5}$,

sendo:

$\mathrm{x}_{1}=$ média dos tratamentos sem micronutrientes;

$\mathrm{x}_{2}=$ média dos tratamentos com micronutrientes via fontes p.a.;

$\mathrm{x}_{3}=$ média dos tratamentos que receberam $250 \mathrm{~kg} \mathrm{ha}^{-1}$ do PFE;

$\mathrm{x}_{4}=$ média dos tratamentos que receberam $500 \mathrm{~kg} \mathrm{ha}^{-1}$ do PFE; $\mathrm{e}$

$\mathrm{X}_{5}=$ média dos tratamentos que receberam $1000 \mathrm{~kg} \mathrm{ha}^{-1} \mathrm{do}$ PFE.

\section{RESULTADOS E DISCUSSÃo}

\section{Produção de matéria seca}

Os dados de produção de MSPA, MSRA e MSTO encontram-se na Tabela 1. Na matéria seca de parte aérea, raízes e total, só ocorreram diferenças significativas entre os contrastes envolvendo micronutrientes na presença de calcário (Tabela 2). Os valores de $\mathrm{Ca}, \mathrm{Mg}$, $\mathrm{Al}$ e $\mathrm{pH}$ originais desse solo, desfavoráveis à cultura do milho, justificam os resultados de baixa produção de matéria seca na ausência de calagem (Tabela 1). O milho caracteriza-se como uma cultura sensível à acidez, ocasionando já no decorrer da fase vegetativa, sérias limitações ao crescimento, apresentando sistema radicular atrofiado e mal desenvolvido, além das folhas mais velhas com coloração arroxeada, típica de deficiência de fósforo (Muzilli et al., 1991; Cantarella, 1993). A mesma sintomatologia foi observada no presente estudo.

Com o aumento das doses do corretivo, verificase que, de um modo geral, ocorreram diferenças acentuadas para a produção de matéria seca entre os tratamentos sem e com micronutrientes, cuja aplicação proporcionou aumentos significativos na produção de biomassa, em relação à testemunha (Tabelas $1 \mathrm{e}$ 2), confirmando a resposta do milho à aplicação de micronutrientes (Berton et al., 1989; Forestieri \& DePolli, 1990).

No nível de calcário de $2 \mathrm{t} \mathrm{ha}^{-1}$ somente ocorreu diferença significativa do contraste entre fontes p.a. e o PFE na produção de matéria seca da parte aérea (Tabela 2). Por sua vez, na dose mais elevada $\left(4 \mathrm{t} \mathrm{ha}^{-1}\right)$ as diferenças foram significativas em relação às três variáveis, e o tratamento com a aplicação de micronutrientes via fontes p.a. aumentou as produções de MSPA, MSRA e MSTO. As maiores produções de matéria seca no tratamento com micronutrientes aplicados via fontes p.a. podem ter ocorrido pela maior solubilidade e disponibilidade dessas fontes em relação ao PFE.

Não ocorreram diferenças significativas entre as combinações de micronutrientes na produção de matéria seca com a adição de doses crescentes do 
PFE (Tabela 2). Entretanto, a adição desse resíduo, em todos os níveis de calcário, mostrou tendência de aumento na produção de biomassa em relação ao tratamento testemunha, inferiores porém àqueles proporcionados pela aplicação via fontes p.a. (Tabela 1). Efeitos positivos da adição de resíduos siderúrgicos aos solos, aumentando a produção de algumas plantas, foram observados por Ribeiro et al. (1986), Louzada (1987), Nogueira (1990) e Amaral (1994). Esses autores verificaram que os efeitos da aplicação dos resíduos sobre a produção das plantas eram superiores aos apresentados pela testemunha. Entretanto, com o aumento no fornecimento, em alguns casos, não se obteve produções maiores, principalmente nas doses mais elevadas do resíduo.

Diferenças de resposta à aplicação de resíduos podem ocorrer por causa das variações em sua composição química, granulometria, origem, dose, tempo de contato e condições do solo. Esses fatores dificultam comparações entre experimentos e expli- cam as diferenças observadas em relação ao presente estudo.

Pode-se observar que o tratamento com micronutrientes via fontes p.a. foi aquele que apresentou tendência de produções relativas maiores independentemente do nível de calcário (Tabela 1), o que indica que as fontes p.a. são mais solúveis favorecendo o fornecimento de micronutrientes para o milho.

$\mathrm{Na}$ ausência da calagem, no tratamento testemunha, as plantas produziram $96 \%$ da produção obtida no tratamento com micronutrientes via fontes p.a.. A produção relativa foi reduzida para $69 \%$ e $37 \%$ nos níveis de 2 e $4 \mathrm{t} \mathrm{ha}^{-1}$ de corretivo, respectivamente (Tabela 1), provavelmente causado pela diminuição da disponibilidade de micronutrientes com o aumento do $\mathrm{pH}$ do solo, em decorrência da aplicação de calcário.

Nas doses de calcário equivalentes a 2 e $4 \mathrm{t} \mathrm{ha}^{-1}$, os tratamentos com aplicação de micronutrientes

TABELA 1. Matéria seca da parte aérea (MSPA), matéria seca das raízes (MSRA), matéria seca total (MSTO) e produção relativa (PR) do milho, em função da calagem e dos tratamentos com micronutrientes e pó de forno elétrico (PFE) (média de 4 repetições).

\begin{tabular}{clcccc}
\hline $\begin{array}{c}\text { Calagem } \\
\left(\mathrm{t} \mathrm{ha}^{-1}\right)\end{array}$ & Tratamento & MSPA & $\begin{array}{c}\text { MSRA } \\
\left(\mathrm{g} \mathrm{vaso}^{-1}\right)\end{array}$ & MSTO & $\begin{array}{c}\text { PR } \\
(\%)\end{array}$ \\
\hline 0 & Testemunha & 7,13 & 1,50 & 86,32 \\
& Fontes p.a. & 8,05 & 0,91 & 8,96 & 100,0 \\
& $250 \mathrm{~kg} \mathrm{ha}^{-1} \mathrm{PFE}$ & 6,17 & 0,75 & 6,92 & 77,23 \\
& $500 \mathrm{~kg} \mathrm{ha}^{-1} \mathrm{PFE}$ & 6,51 & 0,78 & 7,29 & 81,36 \\
& $1000 \mathrm{~kg} \mathrm{ha}^{-1} \mathrm{PFE}$ & 6,39 & 0,74 & 7,13 & 79,57 \\
\hline 2 & Testemunha & 17,50 & 6,87 & 24,37 & 69,37 \\
& Fontes p.a. & 26,11 & 9,02 & 35,13 & 100,0 \\
& 250 kg ha-1 PFE & 22,17 & 8,84 & 31,01 & 88,27 \\
& $500 \mathrm{~kg} \mathrm{ha}^{-1} \mathrm{PFE}$ & 22,28 & 8,60 & 30,88 & 92,54 \\
\hline & $1000 \mathrm{~kg} \mathrm{ha}^{-1} \mathrm{PFE}$ & 23,74 & 8,77 & 32,51 & 36,97 \\
& Testemunha & 9,13 & 2,78 & 11,91 & 100,0 \\
& Fontes p.a. & 24,26 & 9,80 & 34,06 & 78,42 \\
& $250 \mathrm{~kg} \mathrm{ha}^{-1} \mathrm{PFE}$ & 19,10 & 7,61 & 26,71 & 79,24 \\
& $500 \mathrm{~kg} \mathrm{ha}^{-1} \mathrm{PFE}$ & 19,38 & 7,61 & 26,99 & 92,84 \\
\hline
\end{tabular}




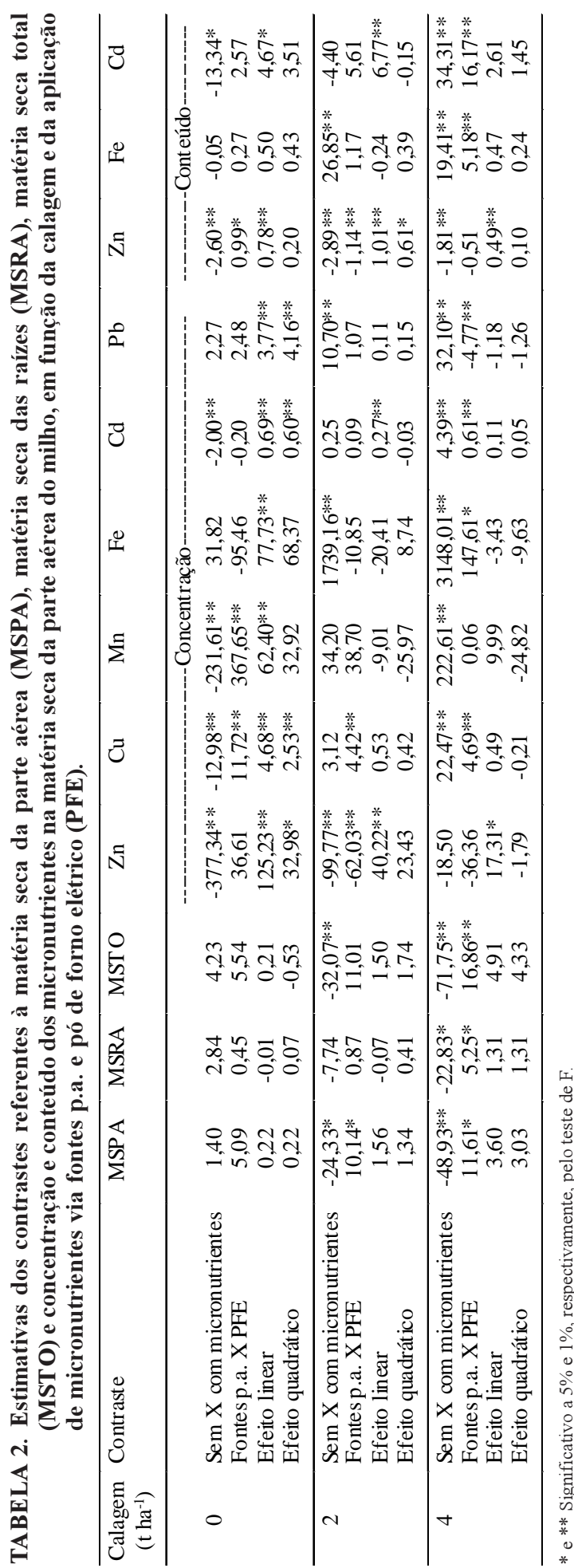

proporcionaram maior produção de biomassa (Tabela 1). Nesse caso, conforme ressaltado anteriormente, a aplicação dos micronutrientes via fontes p.a. foi mais efetiva. Entretanto, quando comparado com a testemunha, a aplicação de PFE proporcionou elevação na MSPA, MSRA e MSTO das plantas de milho, notadamente nos níveis mais elevados de correção do solo (Tabela 1), sugerindo-se que, mesmo com a elevação do $\mathrm{pH}$, de 4,7 para 5,5 e 6,5, o PFE foi efetivo no fornecimento de micronutrientes para o milho.

Por outro lado, na ausência da calagem, a produção relativa das plantas de milho foi menor em função da aplicação do PFE, quando comparada com a testemunha (Tabela 1). Tal comportamento parece estar relacionado com a solubilidade do PFE em função do pH. Nesse caso, uma condição mais ácida favoreceria a solubilidade do PFE e aumentaria a liberação dos elementos desse resíduo, que poderiam até mesmo atingir níveis tóxicos. Uma faixa de $\mathrm{pH}$ menos ácida, obtida pela aplicação do calcário, propiciaria um melhor equilíbrio em relação à disponibilidade dos nutrientes. Deve ainda ser ressaltado que as respostas menores em produção de biomassa, observadas no tratamento sem calagem, além do efeito do PFE, provavelmente, devem-se também aos efeitos diretos e indiretos da acidez natural do solo sobre o crescimento do milho.

\section{Teores e conteúdo de micronutrientes e metais pe- sados na parte aérea do milho}

De modo geral, na ausência de calagem, as concentrações de $\mathrm{Zn}, \mathrm{Cu}, \mathrm{Mn}$ e $\mathrm{Cd}$ foram maiores nos tratamentos que receberam fertilização com micronutrientes (Tabela 3). Com a calagem, observou-se menores concentrações de $\mathrm{Cu}, \mathrm{Mn}, \mathrm{Fe}, \mathrm{Cd}$ e $\mathrm{Pb}$, em relação à testemunha, sugerindo um efeito da correção do solo sobre a solubilidade das fontes, além do efeito de concentração desses metais, nas plantas do tratamento testemunha, pela menor produção de matéria seca (Jarrel \& Beverly, 1981).

Em todos os níveis de calcário ocorreu aumento na concentração de $\mathrm{Zn}$ nos tratamentos com 
micronutrientes, principalmente na presença do PFE. $\mathrm{Na}$ ausência da calagem, os teores de $\mathrm{Zn}$ na matéria seca da parte aérea das plantas de milho foram sensivelmente maiores (Tabela 3), o que pode ser atribuído ao efeito de concentração (Jarrel \& Beverly, 1981), uma vez que nessas condições a biomassa foi bastante reduzida (Tabela 1). Esse comportamento confirma a observação de Nogueira (1990), de que o PFE é uma fonte de $\mathrm{Zn}$. Além desse aspecto, cabe ressaltar a maior solubilidade do PFE decorrente da acidez do solo, uma vez que, na ausência da calagem, a liberação de $\mathrm{Zn}$ por esse resíduo foi maior.

No nível de $2 \mathrm{t} \mathrm{ha}^{-1}$ do corretivo, o PFE quando comparado às fontes p.a. foi bastante eficiente no suprimento de $\mathrm{Zn}$, uma vez que os teores do nutriente são mais elevados em relação ao fornecimento via fontes p.a., a partir da dose de $250 \mathrm{~kg} \mathrm{ha}^{-1}$ (Tabela 3). Na dose mais elevada do PFE, e ausência da calagem, os teores de $\mathrm{Zn}$ na parte aérea das plantas de milho foram bastante elevados. Embora se pudesse esperar toxidez por $\mathrm{Zn}$ nessa condição, influenciando a absorção equilibrada dos outros nutrientes, observa-se que não houve diferenças na produção de MSPA, com o incremento das doses do PFE (Tabela 1). A hipótese da ocorrência de consumo de luxo de Zn pelas plantas de milho não deve ser descartada, conforme sugerido por Amaral (1994).

A aplicação de PFE elevou os teores de $\mathrm{Cd}$ na planta em relação à testemunha, nos tratamentos sem corretivo, enquanto com a calagem esses teores foram reduzidos, sugerindo um efeito de diluição (Jarrel \& Beverly, 1981) causado pela maior biomassa, além da redução na solubilidade do resíduo, com a elevação do $\mathrm{pH}$ do solo (Tabela 3). Além disso, o próprio aumento na disponibilidade de $\mathrm{Zn}$, principalmente nas doses mais elevadas do PFE, pode ter interferido na absorção de Cd (Berton, 1992; Faquin, 1994). Os teores de $\mathrm{Cd}$ nos tratamentos sem calagem na dose de PFE equivalente a $1.000 \mathrm{~kg} \mathrm{ha}^{-1}$ estão acima do limite máximo permitido em alimentos $\left(1,0 \mathrm{mg} \mathrm{kg}^{-1}\right.$, segundo a Associação Brasileira da Indústria de Alimentos, 1985), embora outros autores considerem

TABELA 3. Concentrações de $\mathrm{Zn}, \mathrm{Cu}, \mathrm{Mn}, \mathrm{Fe}, \mathrm{Cd}$ e Pb na matéria seca da parte aérea do milho, em função da calagem e dos tratamentos com micronutrientes e pó de forno elétrico (PFE) (média de 4 repetições).

\begin{tabular}{|c|c|c|c|c|c|c|c|}
\hline \multirow{2}{*}{$\begin{array}{l}\text { Calagem } \\
\left(\mathrm{t} \mathrm{ha}^{-1}\right)\end{array}$} & \multirow[t]{2}{*}{ Tratamentos } & $\mathrm{Zn}$ & $\mathrm{Cu}$ & Mn & $\mathrm{Fe}$ & $\mathrm{Cd}$ & $\mathrm{Pb}$ \\
\hline & & \multicolumn{6}{|c|}{ 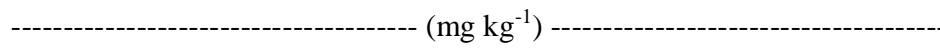 } \\
\hline \multirow[t]{5}{*}{0} & Testemunha & 35,39 & 4,10 & 145,1 & 211,1 & 0,32 & 3,93 \\
\hline & Fontes p.a. & 138,9 & 10,27 & 294,9 & 179,3 & 0,77 & 3,99 \\
\hline & $250 \mathrm{~kg} \mathrm{ha}^{-1} \mathrm{PFE}$ & 69,56 & 4,45 & 146,6 & 183,6 & 0,59 & 1,97 \\
\hline & $500 \mathrm{~kg} \mathrm{ha}^{-1} \mathrm{PFE}$ & 115,7 & 5,52 & 161,4 & 188,3 & 0,63 & 1,77 \\
\hline & $1000 \mathrm{~kg} \mathrm{ha}^{-1} \mathrm{PFE}$ & 194,8 & 9,13 & 209,0 & 261,3 & 1,28 & 5,74 \\
\hline \multirow[t]{5}{*}{2} & Testemunha & 22,91 & 4,79 & 97,81 & 580,3 & 0,41 & 8,48 \\
\hline & Fontes p.a. & 32,35 & 5,11 & 98,93 & 142,8 & 0,37 & 6,07 \\
\hline & $250 \mathrm{~kg} \mathrm{ha}^{-1} \mathrm{PFE}$ & 36,82 & 3,45 & 86,21 & 158,1 & 0,20 & 5,63 \\
\hline & $500 \mathrm{~kg} \mathrm{ha}^{-1} \mathrm{PFE}$ & 45,21 & 3,50 & 94,69 & 143,5 & 0,35 & 5,66 \\
\hline & $1000 \mathrm{~kg} \mathrm{ha}^{-1} \mathrm{PFE}$ & 77,04 & 3,97 & 77,20 & 137,7 & 0,47 & 5,79 \\
\hline \multirow[t]{5}{*}{4} & Testemunha & 28,97 & 10,36 & 120,2 & 947,8 & 1,20 & 14,58 \\
\hline & Fontes p.a. & 24,51 & 5,92 & 64,54 & 197,7 & 0,25 & 5,36 \\
\hline & $250 \mathrm{~kg} \mathrm{ha}^{-1} \mathrm{PFE}$ & 27,68 & 4,07 & 55,39 & 148,6 & 0,01 & 7,34 \\
\hline & $500 \mathrm{~kg} \mathrm{ha}^{-1} \mathrm{PFE}$ & 37,22 & 4,42 & 72,79 & 151,7 & 0,03 & 7,37 \\
\hline & $1000 \mathrm{~kg} \mathrm{ha}^{-1} \mathrm{PFE}$ & 44,98 & 4,56 & 65,38 & 145,2 & 0,11 & 6,15 \\
\hline
\end{tabular}


que esse limite seja maior, entre 5 e $10 \mathrm{mg} \mathrm{kg}^{-1}$ (Mengel \& Kirkby, 1987).

Observa-se, de modo geral, que os teores de $\mathrm{Pb}$ nas plantas de milho aumentaram com as doses do corretivo (Tabela 3). Os teores de $\mathrm{Pb}$ encontrados no tratamento testemunha, nos níveis de 2 e $4 \mathrm{t} \mathrm{ha}^{-1}$ não são consistentes. No nível mais elevado de calcário, as plantas apresentaram maiores teores do metal nos tratamentos com PFE, em relação ao fornecimento via fontes p.a. Os teores de $\mathrm{Pb}$ encontrados nos tratamentos que receberam PFE estão abaixo do limite máximo permitido em alimentos, que é de $8,0 \mathrm{mg} \mathrm{kg}^{-1}$ (Associação Brasileira da Indústria de Alimentos, 1985).

Ressalta-se a preocupação com a composição dos resíduos industriais quando eles são utilizados como fertilizantes. $\mathrm{O}$ acúmulo de micronutrientes e metais pesados deve ser avaliado criteriosamente, uma vez que concentrações altas desses elementos podem levar à toxidez.

No tratamento sem calagem, os teores de Zn, Fe, $\mathrm{Cd}$ e $\mathrm{Pb}$ aumentaram linearmente com a aplicação do PFE (Tabela 3). Por sua vez, com a correção do solo, esse efeito foi bem menos pronunciado, em razão não somente do efeito de diluição, mas também pela menor solubilidade do resíduo nessa condição, causada pela elevação do $\mathrm{pH}$ do solo.

Uma vez que a matéria seca das plantas de milho aumentou sensivelmente com a correção do solo, os conteúdos de $\mathrm{Zn}, \mathrm{Cu}, \mathrm{Mn}, \mathrm{Fe}, \mathrm{Cd}$ e $\mathrm{Pb}$ praticamente acompanharam essa elevação de biomassa (Tabela 4). Observou-se um acentuado incremento no conteúdo de $\mathrm{Pb}$, com a aplicação do corretivo, relacionado provavelmente com a maior quantidade de biomassa produzida, além do que a própria elevação do $\mathrm{pH}$, com a calagem, poderia favorecer a absorção de $\mathrm{Pb}$ (Davies, 1990; Malavolta, 1994), embora existam resultados contraditórios a esse respeito (Kabata-Pendias \& Pendias, 1984).

Precauções devem ser tomadas em relação à utilização dos resíduos industriais e em particular do PFE como fonte de nutrientes, principalmente no que se refere ao acúmulo de metais pesados no solo e nas plantas. Nas condições brasileiras, o monitoramento de metais pesados originado de resíduos industriais deve ser estimulado, para um uso racional.

TABela 4. Conteúdos de $\mathrm{Zn}, \mathrm{Cu}, \mathrm{Mn}, \mathrm{Fe}, \mathrm{Cd}$ e Pb na matéria seca da parte aérea do milho em função da calagem e dos tratamentos com micronutrientes e pó de forno elétrico (PFE) (média de 4 repetições).

\begin{tabular}{|c|c|c|c|c|c|c|c|}
\hline \multirow{2}{*}{$\begin{array}{c}\text { Calagem } \\
\left(\mathrm{t} \mathrm{ha}^{-1}\right)\end{array}$} & \multirow[t]{2}{*}{ Tratamentos } & $\mathrm{Zn}$ & $\mathrm{Cu}$ & $\mathrm{Mn}$ & $\mathrm{Fe}$ & $\mathrm{Cd}$ & $\mathrm{Pb}$ \\
\hline & & \multicolumn{4}{|c|}{ - } & \multicolumn{2}{|c|}{$----\left(\mu\right.$ vaso $\left.^{-1}\right)-----$} \\
\hline \multirow[t]{5}{*}{0} & Testemunha & 0,25 & 0,03 & 1,02 & 1,49 & 2,18 & 28,14 \\
\hline & Fontes p.a. & 1,15 & 0,08 & 2,44 & 1,44 & 6,16 & 33,64 \\
\hline & $250 \mathrm{~kg} \mathrm{ha}^{-1} \mathrm{PFE}$ & 0,46 & 0,03 & 0,91 & 1,17 & 3,55 & 11,84 \\
\hline & $500 \mathrm{~kg} \mathrm{ha}^{-1} \mathrm{PFE}$ & 0,73 & 0,04 & 1,06 & 1,21 & 4,13 & 11,81 \\
\hline & $1000 \mathrm{~kg} \mathrm{ha}^{-1}$ PFE & 1,24 & 0,06 & 1,33 & 1,67 & 8,22 & 37,12 \\
\hline \multirow[t]{5}{*}{2} & Testemunha & 0,40 & 0,08 & 1,71 & 10,15 & 7,20 & 147,90 \\
\hline & Fontes p.a. & 0,83 & 0,13 & 2,57 & 3,73 & 9,71 & 157,90 \\
\hline & $250 \mathrm{~kg} \mathrm{ha}^{-1} \mathrm{PFE}$ & 0,81 & 0,08 & 1,91 & 3,52 & 4,43 & 125,50 \\
\hline & $500 \mathrm{~kg} \mathrm{ha}^{-1} \mathrm{PFE}$ & 1,01 & 0,08 & 2,11 & 3,21 & 7,88 & 125,50 \\
\hline & $1000 \mathrm{~kg} \mathrm{ha}^{-1}$ PFE & 1,82 & 0,09 & 1,83 & 3,28 & 11,19 & 138,20 \\
\hline \multirow[t]{5}{*}{4} & Testemunha & 0,26 & 0,09 & 1,08 & 8,30 & 11,05 & 132,00 \\
\hline & Fontes p.a. & 0,59 & 0,14 & 1,57 & 4,74 & 6,51 & 129,50 \\
\hline & $250 \mathrm{~kg} \mathrm{ha}^{-1} \mathrm{PFE}$ & 0,53 & 0,08 & 1,05 & 2,82 & 0,06 & 139,00 \\
\hline & $500 \mathrm{~kg} \mathrm{ha}^{-1} \mathrm{PFE}$ & 0,72 & 0,09 & 1,43 & 2,93 & 0,64 & 142,50 \\
\hline & $1000 \mathrm{~kg} \mathrm{ha}^{-1}$ PFE & 1,02 & 0,10 & 1,47 & 3,29 & 2,67 & 138,60 \\
\hline
\end{tabular}




\section{CONCLUSÕES}

1. O pó de forno elétrico de siderurgia (PFE) atua como fonte de micronutrientes, especialmente do $\mathrm{Zn}$, no cultivo do milho.

2. A solubilidade do PFE é sensivelmente maior em condições de maior acidez do solo.

3. A presença de $\mathrm{Cd}$ e $\mathrm{Pb}$ no PFE limita seu uso agrícola, principalmente em doses elevadas.

\section{REFERÊNCIAS}

AMARAL, R.D. Avaliação de um resíduo da indústria de zinco como corretivo da acidez e fertilizante do solo e fonte de metais pesados para plantas. Viçosa : UFV, 1994. 70p. Dissertação de Mestrado.

AMARAL SOBRINHO, N.M.B.; COSTA, L.M.; DIAS, I.E.; BARROS, N.F. Aplicação de resíduo siderúrgico em um latossolo: efeitos na correção do solo e na disponibilidade de nutrientes e metais pesados. Revista Brasileira de Ciência do Solo, Campinas, v.17, n.2, p.299-304, maio/ago.1993.

ASSOCIAÇÃO BRASILEIRA DA INDÚSTRIA DE ALIMENTOS (São Paulo, SP). Compêndio da legislação dos alimentos. São Paulo, 1985. não paginado

BANZATTO, D.A.; KRONKA, S.N. Experimentação agrícola. Jaboticabal : FUNEP, 1992. 247p

BATAGLIA, O.C.; RAIJ, B. van. Eficiência de extratores de micronutrientes na análise de solo. Revista Brasileira de Ciência do Solo, Campinas, v.13, n.2, p.205-212, maio/ago. 1989

BERTON, R.S. Fertilizantes e poluição. In: REUNIÃO BRASILEIRA DE FERTILIDADE DO SOLO E NUTRIÇÃO DE PLANTAS, 20., Piracicaba, 1992. Anais. Campinas : Fundação Cargill, 1992. p.299313.

BERTON, R.S.; CAMARGO, O.A.; VALADARES, J.M.A.S. Absorção de nutrientes pelo milho em resposta à adição de lodo de esgoto a cinco solos paulistas. Revista Brasileira de Ciência do Solo, Campinas, v.13, n.2, p.187-192, maio/ago. 1989.

CABRERA, D.; YOUNG, S.D.; ROWELL, D.L. The toxicity of cadmium to barley plants as affected by complex formation with humic acid. Plant and Soil, Dordrecht, v.105, n.2, p.195-204, Feb. 1988.
CANTARELLA, H. Calagem e adubação do milho. In: BÜLL, L.T.; CANTARELLA, H. (Ed.). Cultura do milho: fatores que afetam a produtividade. Piracicaba : POTAFOS, 1993. p.147-196

DAVIES, B.E. Lead. In: ALLOWAY, B.J. (Ed.). Heavy metals in soils. New York: J. Wiley, 1990. p.177196.

EMBRAPA. Serviço Nacional de Levantamento e Conservação de Solos (Rio de Janeiro, RJ). Manual de métodos de análise do solo. Rio de Janeiro, 1979. não paginado.

FAQUIN, V. Nutrição mineral de plantas. Lavras ESAL/FAEPE, 1994. 227p

FORESTIERI, E.F.; DE-POLLI, H. Calagem, enxofre e micronutrientes no crescimento do milho e da mucunapreta num Podzólico Vermelho-Amarelo. Revista Brasileira de Ciência do Solo, Campinas, v.14 n.2, p.167-172, maio/ago. 1990.

FREIRE, J.C.; RIBEIRO, M.A.V.; BAHIA, V.G.; LOPES, A.S.; AQUINO, L.H. Resposta do milho cultivado em casa-de-vegetação a níveis de água em solos da região de Lavras, MG. Revista Brasileira de Ciência do Solo, Campinas, v.4, n.1, p.5-8, jan./abr. 1980

HAGEMEYER, T.; WAISEL, Y. Uptake of $\mathrm{Cd}^{2+}$ and $\mathrm{Fe}^{2+}$ by excised roots of Tomarisc aphylla. Physiologia Plantarum, Copenhagem, v.77, n.4, p.247-253,Apr. 1989

HERNANDEZ, T.; MORENO, J.I.; COSTA, F. Influence of sewage sludge application on crop yields and heavy metal availability. Soil Science and Plant Nutrition, Tokyo, v.37, n.1, p.201-210, Jan./Apr. 1991

JARREL, W.M.; BERVERLY, R.B. The dilution effect in plant nutrition studies. Advances in Agronomy, San Diego, v.34, p.197-224, 1981

KABATA-PENDIAS, A.; PENDIAS, H. Trace elements in soils and plants. Boca Raton : CRC, 1984. 315p.

LOUZADA, P.T.C. Eficiência de uma escória de siderurgia como corretivo e fertilizante do solo. $\mathrm{Vi}_{1}$ çosa : UFV, 1987. 52p. Dissertação de Mestrado.

MALAVOLTA, E. Fertilizantes e seu impacto ambiental: micronutrientes e metais pesados: mitos, mistificação e fatos. Piracicaba : ProduQuímica, 1994. 153p. 
MENGEL, K.; KIRKBY, E.A. Principles of plant nutrition. Berne : International Potash Institute, 1987. $687 \mathrm{p}$.

MUZILLI, O.; OLIVEIRA, E.L.; CALEGARI, A. Manejo da fertilidade do solo. In: INSTITUTO AGRONÔMICO DO PARANÁ (Londrina, PR). A cultura do milho no Paraná. Londrina, 1991. 271p. (IAPAR. Circular, 68).

NOGUEIRA, A.V. Eficiência agronômica como fertilizante de um lodo de esgoto e de dois resíduos provenientes de indústria siderúrgica. Viçosa : UFV, 1990. 85p. Dissertação de Mestrado.

POMBO, L.C.A.; KLAMT, E. Adsorção de zinco e cobre de dois solos do Estado do Rio Grande do Sul. Re- vista Brasileira de Ciência do Solo, Campinas, v.10, n.2, p.191-194, maio/ago. 1986

RIBEIRO, A.C.; FIRME, D.J.; MATTOS, A.C.M. Avaliação da eficiência de uma escória de aciaria como corretivo da acidez do solo. Revista Ceres, Viçosa, v.33, n.187, p.242-248, maio, 1986.

SIDERÚRGICA MENDES JÚNIOR (Juiz de Fora, MG) Resíduos sólidos gerados na S.M.J. Juiz de Fora 1988. não paginado.

VETTORI, L. Métodos de análise do solo. Rio de Janeiro : Ministério da Agricultura-Equipe de Pedologia e Fertilidade do Solo, 1969. 24p. (Boletim Técnico, 7). 